\title{
High Performance Control Strategy of a LCC HVDC System for Power System Enhancement
}

\author{
G. Dharani, Saidarao Nerella
}

\begin{abstract}
It is well-known that traditional LCC HVDC system is not capable of control its reactive strength and terminal $A C$ voltages. This paper investigates the reactive electricity and $A C$ voltages manage at the inverter aspect of the $L C C H V D C$ system with controllable capacitors. The system's capability of operating below poor extinction angle is utilized to reap a wide range of reactive energy control and, mainly, the capacity of exporting reactive electricity. The effectiveness of the reactive strength/voltage control functionality for the proposed device is demonstrated via simulation outcomes the use of actual Time digital Simulator (RTDS). To verify the effectiveness of the reactive electricity and voltage control, $C C C H V D C$ and $L C C$ HVDC with SVC are also set up in RTDS. The proposed idea makes an integration of Fuzzy good judgment which assists in accurate control of capacitors and makes the device green by means of lowering the consumption of Reactive energy. All of the outcomes are acquired from the MATLAB simulations and numerous graphs are plotted.
\end{abstract}

\section{Keywords: LCC-HVDC, RTDS, SVC, FUZZY}

\section{INTRODUCTION}

To have sustainable growth and social progress, it's necessary to satisfy the energy want by utilizing the renewable energy resources like wind, biomass, hydro, co-generation, etc. In sustainable energy system, energy conservation and also the use of renewable source unit are the key paradigm. The need to integrate the renewable energy like wind energy into facility is to form to potential reduces the environmental impact on conventional plant [1]. The integration of wind energy into existing facility presents technical challenges which needs thought of voltage regulation, stability, power quality issues. The power quality is a vital customer-focused measure and is greatly littered with the operation of a distribution and transmission network. The issue of power quality is of nice importance to the turbine [2]. There has been in depth growth and fast development within the exploitation of wind energy in recent years. The individual units is of huge capability up to $2 \mathrm{MW}$, feeding into distribution network, particularly with customers connected in close proximity [3]. Today quite

Revised Manuscript Received on 14 August, 2019.

G.Dharani, Assistant Professor, Department of Electrical \& Electronics Engineering, Malla Reddy Engineering College for WomenMaisammaguda, Secunderabad, Telangana, India

Email: dharanichand.puppala@gmail.com

Saidarao Nerella, Assistant Professor, Department of Electrical \& Electronics Engineering, Malla Reddy Engineering College for Women Maisammaguda, Secunderabad, Telangana, India

Email: saidarao.nerella@gmail.com
28000 wind generating turbines are unit with success operational everywhere in the world. In the fixed-speed turbine operation, all the fluctuation in the wind speed are transmitted as fluctuations in the mechanical torque, electrical power on the grid and leads to large voltage fluctuations. The power quality problems is viewed with relevance to the wind generation, transmission and distribution network, such as voltage sag, swells, flickers, harmonics etc. However the wind generators introduce disturbances into the distribution network.

One of the straight forward strategies of running a wind generating system is to use the induction generator connected on to the grid system. The induction generator has inherent merits of price effectiveness and robustness. However; induction generators require reactive power for magnetization. When the generated active power of an induction generator is varied due to wind, absorbed reactive power and terminal voltage of an induction generator can be significantly affected. A proper Management theme in wind energy generation system is needed under normal operating condition to permit the proper control over the active power production. In the event of increasing grid disturbance, a battery energy storage system for wind energy generating system is generally required to compensate the fluctuation generated by wind turbine. In recent years power electronic converters are unit wide utilized in industrial yet as domestic applications for the control of power flow for automation and energy efficiency. Most of the time these converters draw harmonic current and reactive power from AC supply and causes the power quality issues [9]. STATCOM is most effective for harmonic compensation. Different methods, such as shunt and series active power filters are used effectively [2].

To overcome these problems and also compensatin $\mathrm{g}$ the harmonics and suppressing the reactive power simulta neously due to fluctuating loads. To overcomes the top of disadvantages; STATCOM is best fitted to reactive power compensation and harmonic reduction. It is based on a controllable voltage source converter (VSC). In normal operating system we need a control circuit for the active power production. For reducing the disturbance we have a tendency to use battery storage system. This compensates the disturbance generated by wind turbine. A STATCOM has been projected to improve the power quality. 
This STATCOM technically manages the power quality level related to the commercial wind turbines. This system produces a proper voltage level having power quality improvements. This system provides energy saving and uninterruptible power [5]. The wind energy system is employed to charge the battery as and once wind generation is obtainable The voltage source inverter is controlled by utilizing the current control mode.

The proposed system with battery storage has the subsequent objectives:

- Unity power factor and power quality at purpose of common coupling bus.

- Real and reactive power support only from generator and batteries to load.

- Self operation in case of grid failure. The utility corporations will read this, voltage and power of each system simultaneously by using the online smart metes. The utility can measure power generation of each system simultaneously.

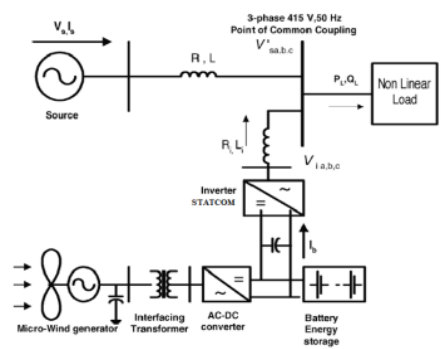

Fig.1 Scheme of wind generator with battery storage [6].

The most used unit to compensate for reactive power within the power systems are either synchronous condensers or shunt capacitors, the latter either with mechanical switches or with thyristor switch, as in Static VAR Compensator (SVC). The disadvantage of using shunt condenser is that the reactive power supplied is proportional to the square of the voltage. Consequently, the reactive power supplied from the capacitors decreases rapidly when the voltage decreases [3] .To overcomes the above disadvantages; STATCOM is best suited for reactive power compensation and harmonic reduction. It is based on a controllable voltage source converter (VSC). The paper study demonstrates the power quality problem due to installation of wind turbine with the grid. In this proposed scheme STATIC COMPENSATOR (STATCOM) is connected at a point of common coupling with a battery energy storage system (BESS) to mitigate the power quality issues. The battery energy storage is integrated to sustain the real power source under fluctuating wind power. The STATCOM control scheme for the grid connected wind energy generation system for power quality improvement is simulated using MATLAB/SIMULINK.

\section{STATIC SYNCHRONOUS COMPENSATOR (STATCOM)}

The STATCOM could be a shunt-connected reactive-power compensation device that's capable of generating and/ or absorbing reactive power and during which the output may be varied to control the particular parameters of an electric power system. It is normally a solid-state switching device capable of generating or absorbing independently controllable real and reactive power at its output terminals once it's fed from an energy supply or energy-storage device at its input terminals. Specifically, the STATCOM, that could be a Voltage-source converter that once fed from a given input of dc voltage, produces a group of 3-phase ac-output voltages, each in phase with and coupled to the corresponding ac system voltage through a comparatively small reactance (which is provided by either an interface reactor or the leakage inductance of a coupling transformer). The dc voltage is provided by an energy-storage capacitor.

A STATCOM based control technology has been planned for improving the power quality which might technically manages the power level associates with the industrial wind turbines. A STATCOM can improve power-system Performance like:

1. The dynamic voltage control in transmission and distribution systems,

2. The power-oscillation damping in power- transmission systems,

3. The transient stability,

4. The voltage flicker control, and

5. The control of not only reactive power but also (if needed) active power in the connected line, requiring a dc energy supply.

A STATCOM is analogous to a perfect synchronous machine that generates a balanced set of three sinusoidal voltages at the fundamental frequency with controllable amplitude and phase angle. This ideal machine has no inertia, is much fast, doesn't considerably alter the existing system ohmic resistance, and might internally generate reactive (both Capacitive and inductive) power.

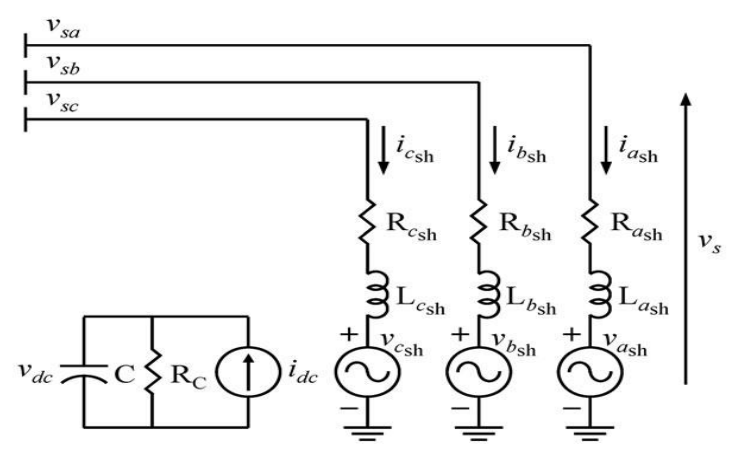

Fig. 2 Equivalent circuit of STATCOM

Fig.2. shows the equivalent circuit of the STATCOM connected to the power system. The reactive power supplied by the STATCOM is either inductive or capacitive depending upon the relative magnitude of fundamental component of vs with respect to vm.

If $\left|v_{m}\right|>\left|v_{s}\right|$, the VSI draws reactive power from the ac bus whereas if $\left|v_{\mathrm{m}}\right|<\left|\mathrm{v}_{\mathrm{s}}\right|$, it supplies reactive power to the ac system. 


\section{POWER QUALITY ISSUES}

\section{A. Voltage Variation:}

The voltage variation issue results from the wind rate and generator torsion. The voltage variation is directly associated with real and reactive power variations. The voltage variation is commonly classified as under:

- Voltage Sag/Voltage Dips.

- Voltage Swells.

- Short Interruptions.

- Long duration voltage variation.

The voltage flicker issue describes dynamic variations within the network caused by turbine or by varying loads. Thus the power fluctuation from turbine happens throughout continuous operation. The amplitude of voltage fluctuation depends on grid strength, network impedance, and phase-angle and power factor of the wind turbines. It is outlined as a fluctuation of voltage in a very frequency 10-35 cycles per second

\section{B. Harmonics:}

The harmonic results because of the operation of power electronic converters. The harmonic voltage and current ought to be restricted to the appropriate level at the point of turbine connection to the network. To ensure the harmonic voltage within the limit, each source of harmonic current can allow only a limited contribution. The rapid switching gives a large reduction in lower order harmonic current com- pared to the line commutated converter, but the output current will have high frequency current and can be easily filter out. The harmonic distortion is assessed for variable speed turbine with a electronic power converter at the point of common connection [9]. The total harmonic voltage distortion of voltage is given as in equation (1)

$$
V_{\mathrm{THD}}=\sqrt{\sum_{h=2}^{40} \frac{V_{n}^{2}}{V_{1}} 100}
$$

Where $\mathrm{Vn}$ is the $\mathrm{nth}$ harmonic voltage and $\mathrm{V}_{1}$ is the fundamental frequency (50) $\mathrm{Hz}$. The THD limit for $132 \mathrm{KV}$ is less than $3 \%$.THD of current ITHD is given as in equation (2)

$$
I_{\mathrm{THD}}=\sqrt{\sum \frac{I_{n}}{I_{1}}} 100
$$

Where $I_{n}$ is the $n^{\text {th }}$ harmonic current and $I_{1}$ is the fundamental frequency (50) $\mathrm{Hz}$ harmonic. The Total harmonic distortion (THD) of current limit for $132 \mathrm{KV}$ is < $2.5 \%$.

\section{Reactive Power:}

Traditional wind turbine is equipped with induction generator. Induction Generator is preferred because they are inexpensive, rugged and requires little maintenance. Unfortunately induction generators require reactive power from the grid to operate. The interactions between wind turbine and power system network are important aspect of wind generation system. When wind turbine is equipped with an induction generator and fixed capacitor are used for reactive compensation then the risk of self excitation may occur during off grid operation. Thus the sensitive equipments may be subjected to over/under voltage, over/under frequency operation and other disadvantage of safety aspect. The effective control of reactive power can improve the power quality and stabilize the grid. The suggested control technique is capable of controlling reactive power to zero value at point of common connection (PCC).

\section{REFERENCE CURRENT GENERATION FOR STATCOM}

Reference current for the STATCOM is generated based on the instantaneous reactive power theory [7][10]. A STATCOM injects the compensation current which is a sum of reactive component current of IG, non-linear load and harmonic component current of non-linear load. P-Q theory offers a generalized definition of fast reactive power, which is valid for sinusoidal or non sinusoidal, balanced or unbalanced, three-phase power systems with or without zero sequence currents and/or voltages.

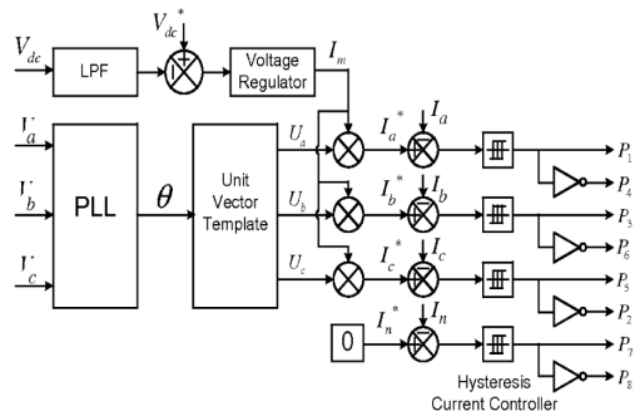

Fig.3. Block diagram representation of grid-interfacing inverter control.

The control diagram of grid- interfacing inverter for a 3-phase 3-wire system is shown in Fig. 3. While performing the power management operation, the inverter is actively controlled in such a way that it always draws/ supplies fundamental active power from/ to the grid. If the load connected to the PCC is non-linear or unbalanced or the combination of both, the given control approach also compensates the harmonics, unbalance, and neutral current. The duty ratio of inverter switches are varied in a power cycle such that the combination of load and inverter injected power appears as balanced resistive load to the grid. The regulation of dc-link voltage carries the knowledge concerning the exchange of active power in between renewable supply and grid. Thus the output of dc-link transformer leads to an active current $(\mathrm{Im})$.

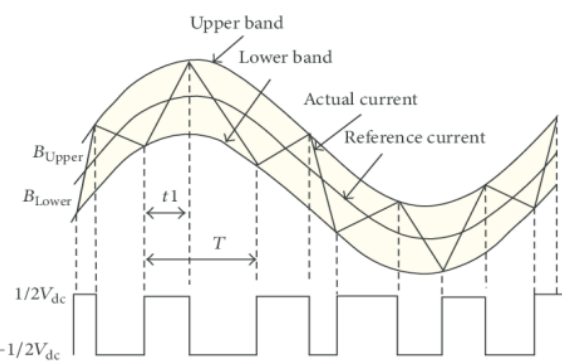

Fig.5. Hysteresis current Modulation

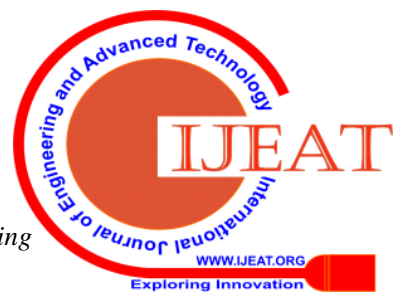


With the hysteresis control, limit bands are set on either side of a signal representing the desired output waveform [6]. The inverter switches are operated as the generated signals within limits. The control circuit generates the sine reference signal wave of desired magnitude and frequency, and it is compared with the actual signal. As the signal exceeds a prescribed hysteresis band, the upper switch in the half bridge is turned $\mathrm{OFF}$ and the lower switch is turned ON. As the signal crosses the lower limit, the lower switch is turned OFF and the upper switch is turned ON. The actual signal wave is thus forced to track the sine reference wave within the hysteresis band limits.

\section{MATLAB MODELEING AND SIMULATION RESULTS}

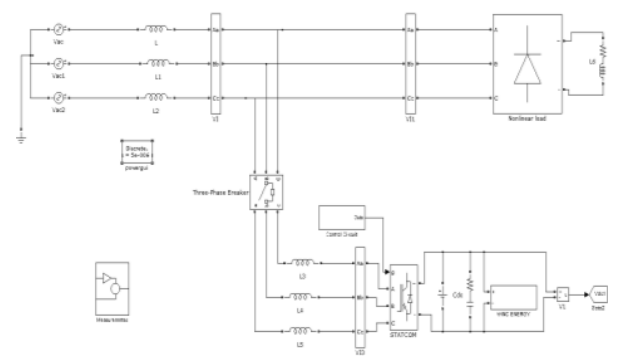

Fig.5 shows the Matlab/simulink model of 3-leg converter with wind energy system

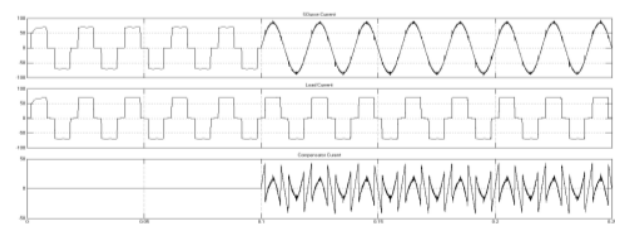

Fig.6 simulated wave forms of proposed system single phase source current, load current and compensator current

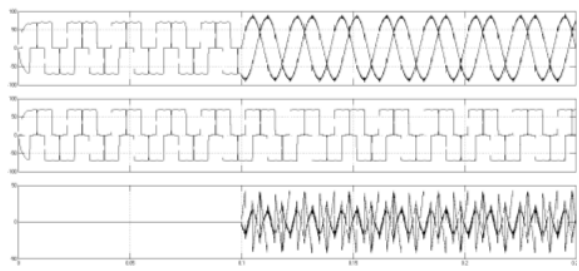

Fig.7 simulated wave forms of proposed system three phase source current, load current and compensator current

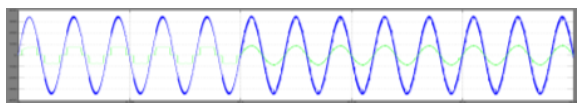

Fig. 8 shows the power factor of 3-leg converter

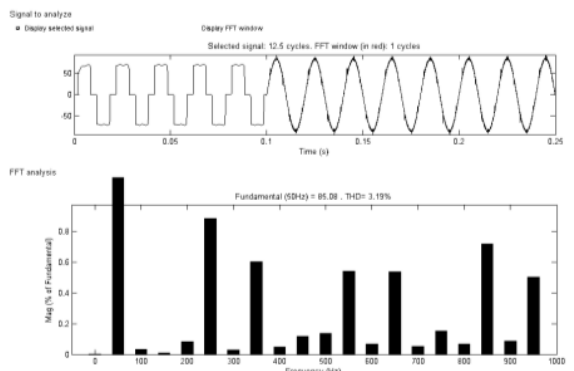

Fig.9 shows the FFT Analysis of 3-leg converter total harmonic distortion value is $3.19 \%$

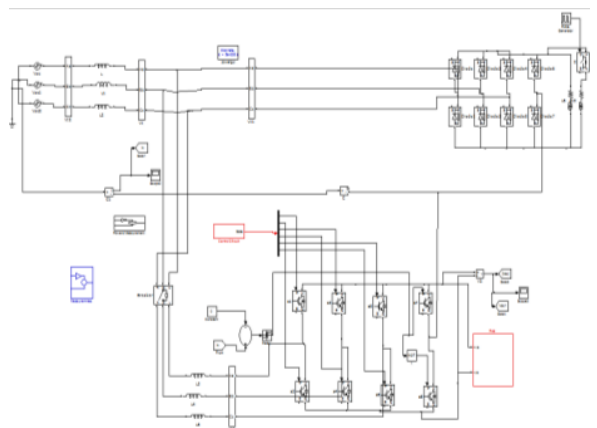

Fig.10 shows the Matlab/simulink model of 4-leg converter

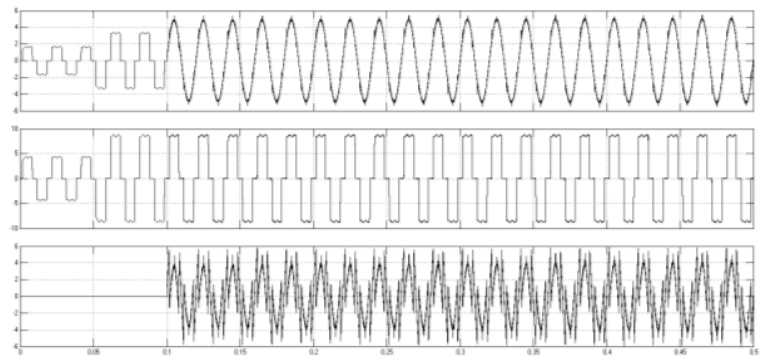

Fig. 11 simulated wave forms of 4-leg converter single phase source current, load current and compensator current

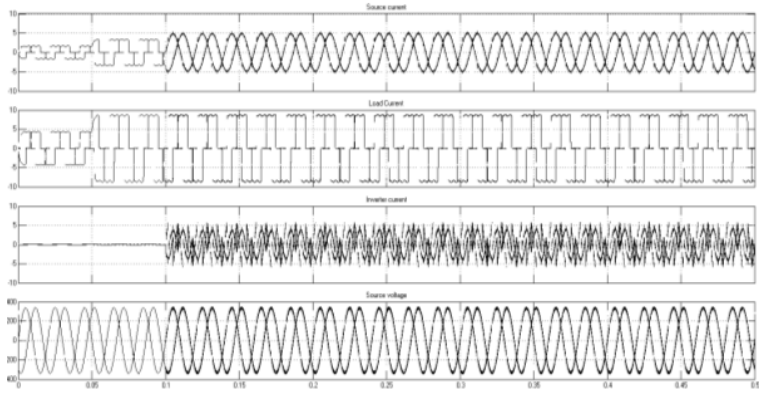

Fig.12 simulated wave forms of 4-leg converter three phase source current, load current, compensator current and neutral current

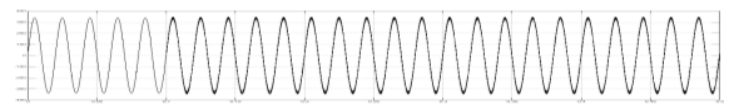

Fig. 13 shows the power factor of 4-leg converter

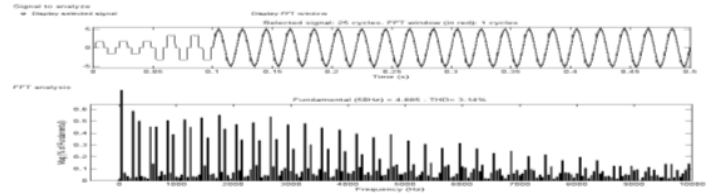

Fig.14 shows the FFT Analysis of 4-leg converter total harmonic distortion value is $3.14 \%$

\section{CONCLUSION}

This paper given Grid Power Quality Improvement in Wind Energy Systems using three leg and four leg converter. The hysteresis current controller is employed to generate the switching signal for inverter in such a way that it will cancel the harmonic current in the system. This control method improves power factor and additionally build harmonic free source current within the distributed network at the PCC.

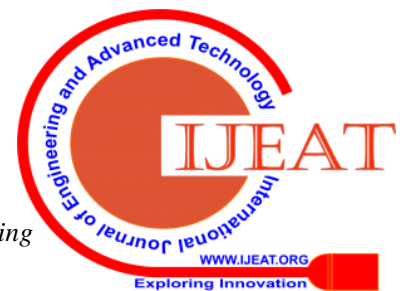


The wind generation exchange is regulated across the dc bus having energy storage and is made available under the steady state condition. This additionally makes real power flow at fast demand of the load. Rapid injection or absorption of reactive/real power flow within the power system can be made possible through battery energy storage and static compensator. Battery energy storage provides rapid response and enhances the performance under the fluctuation of turbine output and improves the voltage stability of the system.

\section{REFERENCES}

1. O. B. Nayak, A. M. Gole, D. G. Chapman, and J. B. Davies, "Dynamic performance of static and synchronous

2. compensators at an HVDC inverter bus in a very weak $\mathrm{C}$ system," IEEE Transactions on Power Systems, vol. 9, pp. 1350-1358, 1994

3. M. De Oliveira, M. Poloujadoff, A. Le Du, and P. G. Therond, "Supply of an entirely passive AC system through an HVDC link," International Journal of Electrical Power \& Energy Systems, vol. 16, pp. 111-116, 1994.

4. J. W. Feltes, B. D. Gemmell, and D. Retzmann, "From Smart Grid to Super Grid: Solutions with HVDC and FACTS for grid access of renewable energy sources," in 2011 IEEE Power and Energy Society General Meeting, 2011, pp. 1-6.

5. S. V. Bozhko, R. Blasco-Gimenez, L. Risheng, J. C. Clare, and G. M. Asher, "Control of offshore DFIG-based wind farm grid with LineCommutated HVDC connection," IEEE Transactions on Energy Conversion,vol. 22, pp. 71-78, 2007.

6. L. Yong, L. Longfu, C. Rehtanz, S. Ruberg, and L. Fusheng, "Realization of reactive power compensation

7. near the LCC-HVDC converter bridges by means of an inductive filtering method," IEEE Transactions on Power Electronics, vol. 27, pp. 3908-3923, 2012.

8. N. Nithiyanandam, K. Venkatesh, M. Rajesh, Transfer The Levels Of The Monitored Carbon, Nitrogen Gases From The Industries, International Journal of Recent Technology and Engineering, Volume-7 Issue-6S3 April, 2019.

9. Sivanesh Kumar, A., Brittoraj, S., Rajesh, M., Implementation of RFID with internet of things, Journal of Recent Technology and Engineering, Volume-7 Issue-6S3 April, 2019.

10. Rajesh, M., Sairam, R., Big data and health care system using mlearningJournal of Recent Technology and Engineering, Volume-7 Issue-6S3 April, 2019.

11. Rajesh, M., and J. M. Gnanasekar. "Path Observation Based Physical Routing Protocol for Wireless Ad Hoc Networks." Wireless Personal Communications 97.1 (2017): 1267-1289. 